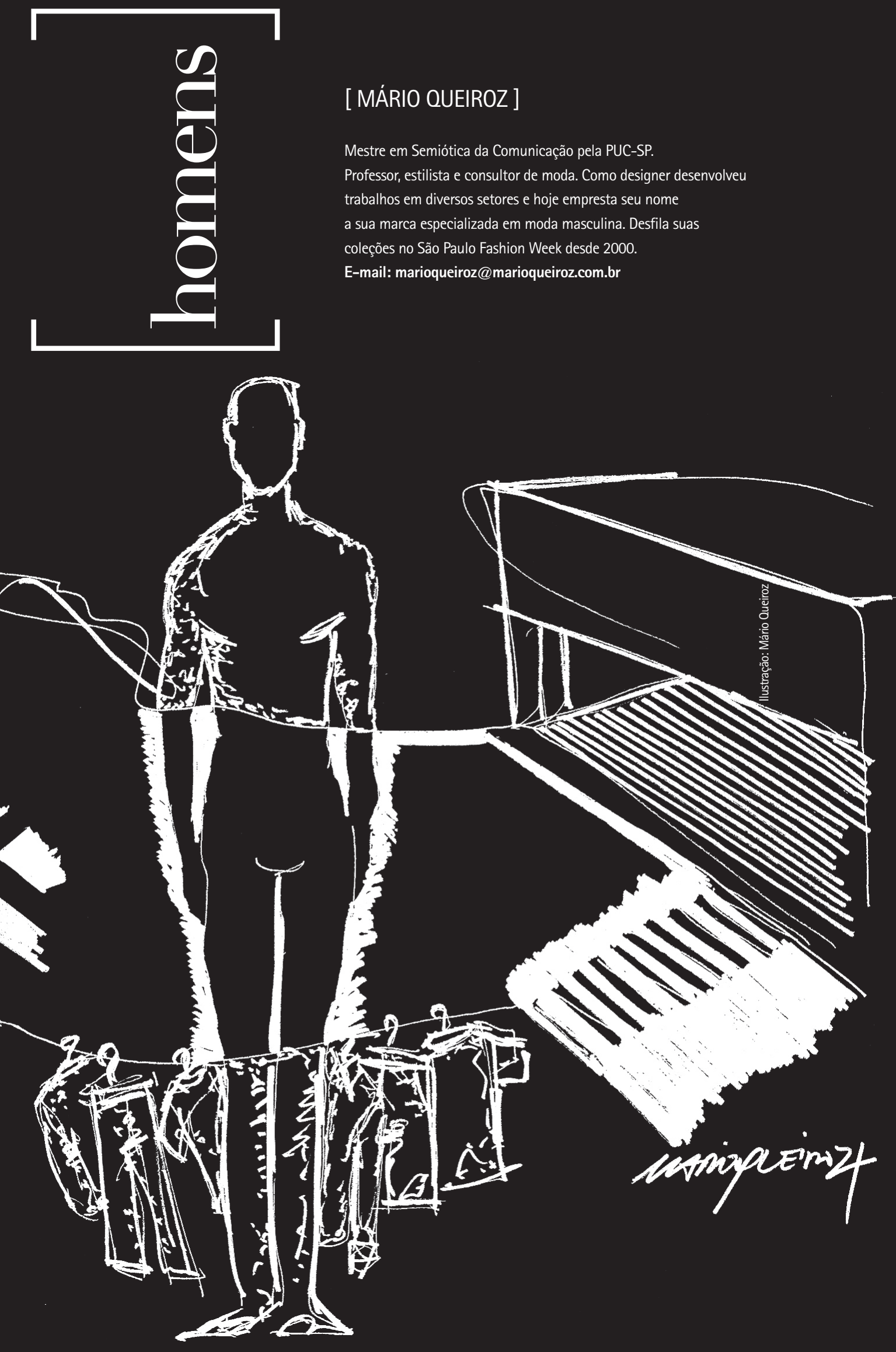

\title{
Homens que inventaram Moda
}


Começo a imaginar de que material somos feitos - pessoas que estudam, trabaIham e vivem com a moda há pelo menos vinte anos. Penso em como vivenciamos um novo cenário brasileiro da moda... jovens sem acesso a esta velocidade de informação atual, mas de olhos abertos e muita disposição.

Em meados da década de 1980, nós que vivíamos no eixo Rio-São Paulo e os que vinham de todas as regiões do país em busca da modernidade metropolitana sofríamos os resquícios da ditadura e éramos completamente influenciados pelas gerações anteriores; cultuávamos os mesmos ídolos de esquerda e toda a vanguarda artística. Essa geração pré-internet, mesmo sem dinheiro, transitava muito bem da praia de Ipanema à avenida Paulista e vice-versa. As duas capitais tinham suas caracteristicas próprias e esses jovens queriam ao mesmo tempo os mergulhos nas águas cariocas e a ebulição da pauliceia desvairada.

Havia muito para refletir, mesmo tratando-se de uma geração considerada alienada, fruto da censura que tinha marcado os anos anteriores. A questão de gêneros era, certamente, um dos assuntos. Herdamos a ousadia e a rebeldia, assim como os padrões engessados de nossa cultura machista. Algumas brechas se abriam, motivadas pelas atitudes irreverentes de Fernando Gabeira, naquele momento jornalista e escritor, ou mesmo pela androginia espetacular de Ney Matogrosso.

Em São Paulo, a informação era agressiva, traduzida nas imagens dos simpatizantes dos punks e de outros movimentos ingleses em espaços como o Madame Satã, casa noturna famosa entre os anos 1980 e 1990. Até mesmo os cariocas eram contaminados por essa onda, e os jovens que não gostavam de sol e praia preferiam as noites do Crepúsculo de Cubatão, boate que funcionou de 1984 a 1989, em Copacabana. Mas, antes disso, o Rio havia sido o grande referencial, inclusive para a moda. Se os showrooms de pronta-entrega ficavam em Copacabana, a referência de atitude vinha mesmo de Ipanema.

Nos anos 1980, em Ipanema, havia uma loja completamente diferente e que representou uma grande mudança na moda masculina. Na concepção do estilista Luiz de Freitas, a Mr. Wonderful, como seu nome sinalizava, possibilitava aos homens serem tão maravilhosos - na ousadia de suas produções - quanto as mulheres. A loja, exclusivamente para homens, era repleta de peças coloridas, evidenciando que o universo da moda masculina não era feito apenas de repetidos padrões. A surpresa não vinha só das cores e das estampas, mas também das formas inovadoras. Há vinte

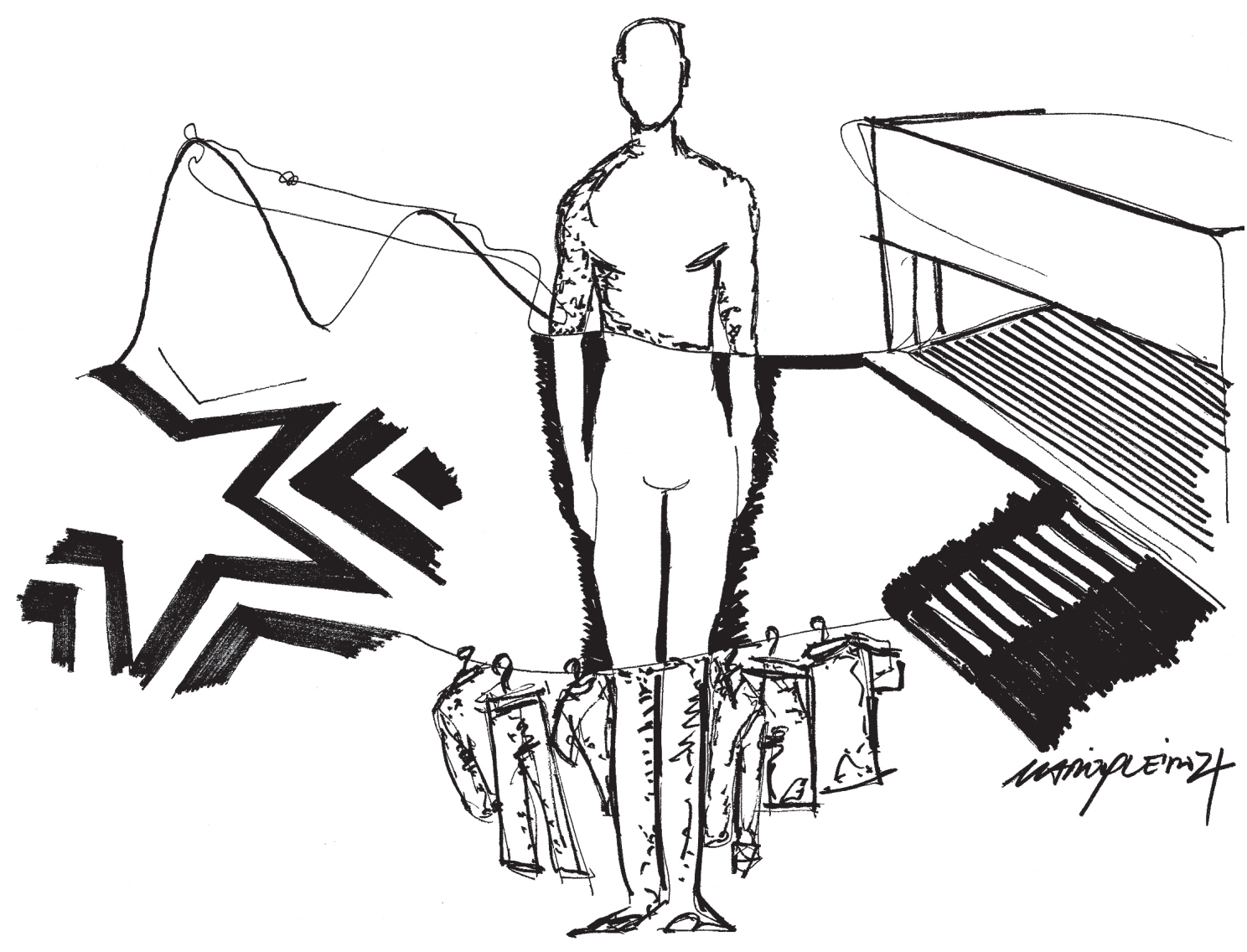


anos, Luiz de Freitas renovava nas modelagens de calças e difundia os chamados "camisões" - camisas muito amplas, de ombros caídos, com cores supervivas e combinações hipercontrastantes.

Outras marcas cariocas surgiram trazendo, junto com a moda feminina, um novo espaço para os homens - com mais descontração e ousadia. Diferentemente do trabalho exclusivo de um estilista, a Yes Brazil introduziu novidades tanto na produção quanto na distribuição - suas peças eram comercializadas em lojas multimarcas de todo o país. Seu criador, Simão Azulay, com sua moda colorida e irreverente, fez da Yes Brazil um dos destaques entre as grandes grifes de jeans que surgiram "made in Rio". Por outro lado, a praia era uma forte referência para o beachwear e para o surfwear, que avançava pelas cidades mais distantes do mar. Atendendo a esses segmentos, surgiu a Company, um jeito carioca de interpretar o espírito californiano dos surfistas que não se limitava aos bermudões de náilon e camisetas de inspiração Hang-Ten, famosa marca americana voltada para o surfe e o skate.

A moda carioca vendia um clima de festa; vendia a imagem do jovem carioca que se dividia entre o Posto 9, noites disco no Morro da Urca, cineclubes e o final de um período de manifestações políticas. Ipanema era símbolo de longas tardes de verão, de noites de domingo pós-praia no teatro. A geração que assistiu ao grupo de teatro Asdrúbal Trouxe o Trombone se via no palco: entre drogas, dúvidas e uma grande vontade de "curtição".

Mas, nos anos 1990, a "Moda Rio" perdeu espaço, e os olhares se voltaram para a terra da garoa. Além de marcas e estilistas que apareciam com força e vendendo para todo o Brasil, os "alternativos" paulistanos se faziam presentes em incriveis brechós, como o Universo em Desfile ou o Caos Brasilis.

Nesse momento, eu já vivia em São Paulo trabalhando como estilista freelance. Fui da primeira geração de designers de surfe e streetwear. Atuei na OP - Ocean Pacific -, do lendário Cidão, e na Vision Street Wear, de Alberto Turco Hiar, que anunciava pessoalmente suas grandes promoções na TV. As empresas que me procuravam eram em sua maioria voltadas ao setor masculino e houve um período em que eu atendia ao mesmo tempo marcas de "mauricinhos" e também grifes de skatistas.

A expansão da moda brasileira estava começando a surgir, trazida pelas mãos de figuras como Pazetto e Paulo Borges. Foi num evento de Paulo Borges e de Cristiana Arcangeli - o Phytoervas - que, em 1994, um show causou uma grande surpresa. 0 desfile que roubou a atenção de todos não era feminino. Jorge Kaufmann apresentou na passarela a sensualidade masculina por meio de uma leitura pop de todos os arquétipos. Havia humor, e talvez estivesse aí o enorme sucesso. Nesse show os homens estavam à vontade e pareciam adorar e saber perfeitamente tirar proveito da moda. 0 desfile significou um impulso na vontade dos designers que gostavam da moda masculina, mas que nas empresas em que atuavam não tinham espaço para demonstrar todo seu talento e desejo de inovação. Com o surgimento de novas apresentações, emergiram também as oportunidades para esses estilistas - e posso dizer que fiz parte desse pequeno grupo - que decidiram lançar suas próprias marcas. Foi, certamente, em eventos como o Phytoervas Fashion e a Casa de Criadores, de André Hidalgo, que esses designers se destacaram. Nessa época apareceram as sungas estampadas com imagens de santos de Jum Nakao e os rapazes com traseiros aparentes de Jeziel Moraes. Minha coleção Meninos Grandes - inspirada nos conjuntos infantis que os meninos dos anos 1970 usavam - foi apresentada na Semana Barra Shopping de Moda da Dupla Assessoria e alguns looks participaram ainda do desfile do Mercado Mundo Mix no Phytoervas Fashion, o que nos leva a pensar o quanto as grandes oportunidades da moda se cruzavam naquele momento. 0 Mercado Mundo Mix foi uma experiência significativa: um maravilhoso "circo-feira-dancing" onde jovens estilistas demonstravam que sabiam fazer moda tanto na passarela quanto nas ruas.

Repensar essa história recente da moda brasileira é importante não só para alimentar a nova geração, mas para que todos nós que estamos atuando no mercado possamos refletir o quanto esses acontecimentos fizeram parte de nossa formação. Do mesmo modo, é relevante pensar no quanto a discussão sobre a moda masculina cresceu e amadureceu, tornando possível hoje falarmos de novos segmentos e de novas possibilidades para o estilo do homem brasileiro. Há muito para se lembrar e pesquisar e, certamente, para se fazer. 